\title{
Platform Stress in Hospitality - Focusing on the Technology dimension
}

\author{
Jae Eun (Francesca) Park (D), Namho Chung (D), \\ and Chulmo $\mathrm{Koo}^{(\bowtie)}$ (DD \\ Smart Tourism Education Platform, Kyung Hee University, Seoul, South Korea \\ \{francesca.jep, nhchung, helmetgu\}@khu.ac.kr
}

\begin{abstract}
For the emergence of platform business, it is important to manage the stress that hosts receive from the business. Considering the characteristics of the platform business, stressors arise from social and technology dimension. In the global platform business (e.g., Airbnb), social dimension stressors mostly arise from the relationships among stakeholders, and technology dimension stressors arise from the system they utilize. This research aims to define this combination of social and technology stress as "Platform Stress." Especially focusing on the technology dimension, this research empirically verified the relations of techno-stressors, burnout, and switching intention. Further, mediating effects of burnout in between the relationships demonstrates the importance of investigating the hosts' stress. Exploring the platform stress from the technology-usage perspective, this research provides theoretical and managerial implications.
\end{abstract}

Keywords: Platform stress $\cdot$ Platform business $\cdot$ Technostress $\cdot$ Airbnb

\section{Introduction}

Disruptive development of Information Communication Technologies (ICTs) over the last decade generated the new type of business model: platform business [1]. Among the various platform businesses in overall industries, Airbnb is a typical example in the hospitality, especially accommodation industry [2].

Much research has been conducted regarding the platform businesses focusing on the relationship in it [3, 4]. However, most of these studies aim at guests whereas insufficiently aimed at hosts [5]. Furthermore, although the platform businesses have been growing fast in various industries, few research has investigated the strain hosts go through. Particularly, stress from the platform business is unique in that it is caused by both social and technological issues considering the peer-to-peer service-providing and at the same time technology-based characteristics of the business.

This work was supported by the Ministry of Education of the Republic of Korea and the National Research Foundation of Korea (NRF-2019S1A3A2098438)

(C) The Author(s) 2022

J. L. Stienmetz et al. (Eds.): ENTER 2022, Information and Communication

Technologies in Tourism 2022, pp. 304-309, 2022.

https://doi.org/10.1007/978-3-030-94751-4_27 


\section{Literature Review}

\subsection{Platform Business and Its Complaints}

Platform business is made upon the relationships between stakeholders (e.g., in case of Airbnb, guests, peer hosts, and employees of the platform company) who make transactions and the ICTs that make the online transactions possible. It can be said that platform is composed of two dimensions: social dimension and technology dimension.

In the social dimension, hosts may perceive the relationship with the headquarters, customers, and peer hosts as stressors [6]. In addition, hosts may feel the transformations relatively abrupt and perceive it as stressor since individuals have to learn such things by themselves.

Against this backdrop, we define this specific stress that occurs from the social and technology dimensions of the platform business as "platform stress." In this research, we focused on the technology dimension and the further will be discussed below.

\subsection{Platform Stress in the Technology Dimension - Technostress}

Technology gave pressure to users, in our research hosts, who are not accustomed to the technology and thus have difficulty in handling it. This adaptation problem "caused by and inability to cope with the new computer technologies" was coined as "technostress" [7]. From the various previous study, researchers categorized these stressors mentioned above into 5 types: work-overload, complexity, uncertainty, job-insecurity, and job-invasion [8]. In this research, we focused on the first 3 factors since the platform business if far from job-insecurity and job-invasion, and rather created the opportunity on the basis of technology (Table 1).

Table 1. Definition of independent variables

\begin{tabular}{l|l}
\hline Variable & Definition \\
\hline PTC & $\begin{array}{l}\text { The state which technology makes users feel inadequate and forces them to spend } \\
\text { time and effort in learning and understanding it [8] }\end{array}$ \\
\hline PTU & $\begin{array}{l}\text { The state which technology continues to changes and upgrades and makes users } \\
\text { unsettle and create uncertainty [8] }\end{array}$ \\
\hline PWL & The state which the technology force users to work faster and longer [8] \\
\hline
\end{tabular}

Meanwhile, the technology dimension from platform stress is not the same with technostress. Platform stress is the specific burnout that service providers in the P2P platform business experience due to the relational and technological issues. Therefore, the former indicates the burnout that platform service providers (e.g., Airbnb hosts) experience and it may be the trigger for service providers to leave the platform whereas the employees experiencing the latter might not leave their organization since they are not individual business runners. 


\section{Research Model and Hypotheses Development}

Technology as a stress factor causes hosts to feel burnout, which may ultimately make them leave the platform. Thus, we hypothesized as following:

H1a-3a: Platform technology complexity, -uncertainty, and -work overload is positively related to burnout.

HIb-3b: Platform technology complexity, -uncertainty, and -work overload is positively related to switching intention.

When employees feel a sense of strain, they no longer want to stay in the organization and instead hope to leave, which can be interpreted that the employees' burnout affects their switching intention [9]. Accordingly, people who work in stressful conditions are more likely to undergo burnout, and this burnout arises switching intention [10]. Therefore, we hypothesized as following (Fig. 1):

H4: Burnout is positively related to switching intention.

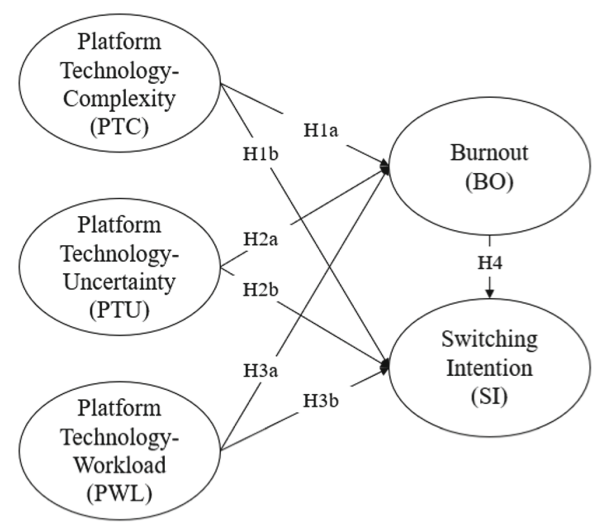

Fig. 1. Research model

\section{Research Methodology}

\subsection{Data Collection}

Measurement items were taken from prior literature, and content validity was checked to identify ambiguous definitions or questions that are difficult to answer. The survey was conducted through the online survey platform Qualtrics to the members of Airbnb hosts' internet community (Feb 23, 2021-Mar 07, 2021). Considering the statistical technique employed, the sample size was checked based on $\mathrm{G}^{*}$ Power [11]. According to this, testing the proposed model required a minimum sample of 110 individuals for a statistical power of 0.95 . Therefore, it can be safely concluded that the sample size used (157) was acceptable for the purposes of our research. Descriptive details such as 
gender (Male 47.13\%, Female 52.87\%) and age were almost equally distributed, whereas in location Seoul, the capital city, took half of the percentage (51.6\%).

\subsection{Results}

Through partial least squares SEM (PLS-SEM) analyses using SmartPLS 3.0 [12], Cronbach's alpha and composite reliabilities all exceeded the threshold value of 0.70 , all indicator loadings and all AVE values exceed each threshold value of 0.60 and 0.50 cut-off, supporting convergent validity. Fornell and Larcker criterion and the factor loading were confirmed supporting discriminant validity.

As Table 2 shows, hypotheses regarding the relations of each stressor and burnout are all supported, whereas relations of switching intention are all rejected. In addition, the relations of burnout and switching intention is supported. It demonstrates that stressors do not directly provoke platform switching intention but do indirectly provoke when burnout mediates in between. Further, the $\mathrm{R}^{2}$ values for dependent variable burnout and switching intention were 0.53 and 0.32 , respectively.

Table 2. Result of hypotheses testing

\begin{tabular}{l|l|l|l|l}
\hline Hypothesis & Path & $\beta$ & P & Result \\
\hline H1a & PTC $\rightarrow$ BO & 0.284 & $0.001^{* *}$ & Supported \\
\hline H1b & PTC $\rightarrow$ SI & 0.029 & 0.788 & Rejected \\
\hline H2a & PTU $\rightarrow$ BO & 0.243 & $0.003^{* *}$ & Supported \\
\hline H2b & PTU $\rightarrow$ SI & 0.161 & 0.184 & Rejected \\
\hline H3a & PWL $\rightarrow$ BO & 0.352 & $0.000^{* * *}$ & Supported \\
\hline H3b & PWL $\rightarrow$ SI & 0.220 & 0.062 & Rejected \\
\hline H4 & BO $\rightarrow$ SI & 0.274 & $0.013^{*}$ & Supported \\
\hline
\end{tabular}

\subsection{Mediating Effects}

To further examine the mediating effects of burnout, our research conducted VAF analysis through PLS-SEM bootstrapping technique [13]. Table 3 shows the result that burnout has partial mediating effects on the relationships between each of PTC, PTU,

Table 3. Result of mediating effects testing

\begin{tabular}{l|l|l|l|l|l}
\hline Path & Coeff of P1 & Coeff of P2 & Coeff of P3 & VAF & Result \\
\hline PTC $\rightarrow$ BO $\rightarrow$ SI & $0.284^{* *}$ & $0.274 *$ & 0.029 & 0.729 & Partial mediation \\
\cline { 1 - 1 } PTU $\rightarrow$ BO $\rightarrow$ SI & $0.243^{* *}$ & & 0.161 & 0.293 & Partial - \\
\cline { 1 - 1 } PWL $\rightarrow$ BO $\rightarrow$ SI & $0.352^{* * *}$ & & 0.220 & 0.305 & Partial - \\
\hline
\end{tabular}

Note: $\mathrm{P} 1=$ independent variable(iv) $\rightarrow$ mediator $(\mathrm{m}), \mathrm{P} 2=$ mediator $(\mathrm{m}) \rightarrow$ dependent variable $(\mathrm{dv}), \mathrm{P} 3=$ independent variable(iv) $\rightarrow$ dependent variable $(\mathrm{dv}) ; \mathrm{VAF}=(\beta \mathrm{iv}-\mathrm{m} *$ $\beta \mathrm{m}-\mathrm{dv}) /(\beta \mathrm{iv}-\mathrm{m} * \beta \mathrm{m}-\mathrm{dv}+\beta \mathrm{iv}-\mathrm{dv})$, More than $.80=$ full mediation; $.20-.80=$ partial mediation; Less than $.20=$ no mediation. 
PWL and SI. It can be interpreted that while stressors of platform technology complexity, -uncertainty, and -work overload do not directly arise switching intention, it merely does when mediated by burnout.

\section{Conclusions}

We tried to explore the new type of stress and newly defined it as "Platform Stress." This research especially focused on the technology dimension, reflecting the dependency technology dimension, and highlighting the importance of it. Theoretical implication is provided by extending the understanding of technostress and proposing the concept of platform stress. Managerial implication is provided by suggesting that not only stressors themselves, but also controlling burnout is essential to keep hosts from leaving the platform. Limitations of the research are found in restricted platform (Airbnb), market (South Korea), and industry (accommodation). Future research is expected to be conducted in more diverse platform, market, and industry.

\section{References}

1. Wirtz J, So KKF, Mody MA, Liu SQ, Chun HH (2019) Platforms in the peer-to-peer sharing economy. J Serv Manag 30(4):452-483

2. Pînzaru FM, Mitan A, Mihalcea AD (2018) Reshaping competition in the age of platforms: the winners of the sharing economy. In: Vătămănescu E-M, Pînzaru FM (eds) Knowledge management in the sharing economy, vol 6. KMOL. Springer, Cham, pp 19-38. https://doi. org/10.1007/978-3-319-66890-1_2

3. Lin PM, Fan DX, Zhang HQ, Lau C (2019) Spend less and experience more: understanding tourists' social contact in the Airbnb context. Int J Hosp Manag 83:65-73

4. Park S, Tussyadiah IP (2020) How guests develop trust in hosts: an investigation of trust formation in P2P accommodation. J Travel Res 59(8):1402-1412

5. Lee H, Yang SB, Koo C (2019) Exploring the effect of Airbnb hosts' attachment and psychological ownership in the sharing economy. Tour Manage 70:284-294

6. Shaukat R, Yousaf A, Sanders K (2017) Examining the linkages between relationship conflict, performance and turnover intentions: role of job burnout as a mediator. Int $\mathrm{J}$ Conf Manag 28(1):4-23. https://doi.org/10.1108/IJCMA-08-2015-0051

7. Brod C (1982) Managing technostress: optimizing the use of computer technology. Pers J 61 (10):753-757

8. Tarafdar M, Tu Q, Ragu-Nathan BS, Ragu-Nathan TS (2007) The impact of technostress on role stress and productivity. J Manag Inf Syst 24(1):301-328

9. Shi X, Gordon S, Tang CH (2021) Momentary well-being matters: Daily fluctuations in hotel employees' turnover intention. Tour Manag 83:104212

10. Sonnentag S, Fritz C (2007) The recovery experience questionnaire: development and validation of a measure for assessing recuperation and unwinding from work. J Occup Health Psychol 12(3):204

11. Faul F, Erdfelder E, Lang AG, Buchner A (2007) G* power 3: a flexible statistical power analysis program for the social, behavioral, and biomedical sciences. Behav Res Methods 39 (2):175-191 
12. Hair JF, Ringle CM, Sarstedt M (2011) PLS-SEM: indeed a silver bullet. J Market Theory Pract 19(2):139-152

13. Hair Jr JF, Hult GTM, Ringle CM, Sarstedt M (2021) A primer on partial least squares structural equation modeling (PLS-SEM). Sage publications

Open Access This chapter is licensed under the terms of the Creative Commons Attribution 4.0 International License (http://creativecommons.org/licenses/by/4.0/), which permits use, sharing, adaptation, distribution and reproduction in any medium or format, as long as you give appropriate credit to the original author(s) and the source, provide a link to the Creative Commons license and indicate if changes were made.

The images or other third party material in this chapter are included in the chapter's Creative Commons license, unless indicated otherwise in a credit line to the material. If material is not included in the chapter's Creative Commons license and your intended use is not permitted by statutory regulation or exceeds the permitted use, you will need to obtain permission directly from the copyright holder. 